\title{
Mechanical properties of TiAl fabricated by electron beam melting - A review
}

\author{
Bo-chao Lin', *Wei Chen ${ }^{1,2,3,4}$ \\ 1. AVIC Manufacturing Technology Institute, Beijing 100024, China \\ 2. Key Laboratory on Power Beam Processing, Beijing 100024, China \\ 3. Beijing Key Laboratory on Power Beam Metal Additive Manufacturing Technology and Equipment, Beijing 100024, China \\ 4. Aviation Key Laboratory of Science and Technology on Additive Manufacturing, Beijing 100024, China
}

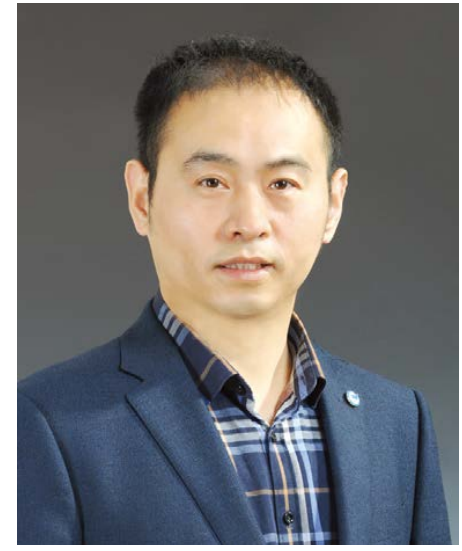

\section{*Wei Chen}

Prof. Chen received his Ph.D. from Michigan State University, United States. Before joining AVIC Manufacturing Technology Institute in 2013 , he was a postdoctoral fellow at the Materials Science and Technology Department of Oak Ridge National Lab. Prof. Chen is now the technical committee director of the Key Laboratory of Power Beam Processing. His research interest includes powder metallurgy, additive manufacturing, power beam welding, fatigue and creep behavior of $\mathrm{Ti}$ alloys. He has published over 50 research papers and 2 book chapters, and holds 6 patents. He also works on materials designing and received the R\&D 100 Awards (2012) for his patent on nanocomposites used in the mining and drilling industry.

E-mail: werner_nju@163.com
Abstract: As a typical intermetallic material, TiAl is inevitably difficult to process by conventional methods. Additive manufacturing (AM) has recently become a new option for making net-shape TiAl components. Among all AM methods, electron beam melting (EBM) shows the potential to make TiAl components with good mechanical properties and is used for low pressure turbine blades. The mechanical properties, including tensile and compression properties, fracture toughness, fatigue and creep properties of EBM TiAl are reviewed and compared to the conventionally fabricated alloys. Results show that the tensile strength of EBM alloys is higher than cast alloys, and other properties are comparable to the cast/forged alloys. The sensitivity of mechanical properties and microstructure to EBM processing parameters is presented. Issues including layered microstructure, anisotropy in mechanical properties, and fatigue failure from defects are also reviewed. Finally, some opportunities and challenges of EBM TiAl are identified.

Key words: additive manufacturing; electron beam melting; TiAl alloy; mechanical properties; tensile; fatigue

CLC numbers: TG146.23; Document code: A;

Article ID: 1672-6421(202104-307-10

\section{Introduction}

Titanium aluminide (TiAl), with its low density, high specific strength, high specific modulus, good creep, and oxidation resistance, has been considered a potential replacement of Ni-based superalloys at temperatures between $600-900{ }^{\circ} \mathrm{C}^{[1,2]}$. GE is the pioneer in the industrial application of TiAl and successfully introduced TiAl low pressure turbine blades into the GEnx engines in $2011^{[3]}$.

The poor ductility and machinability of TiAl makes near-net-shape processing like additive manufacturing (AM) an ideal method. The AM technologies utilized in the manufacturing of TiAl include laser metal deposition (LMD), selective laser melting (SLM) and electron beam melting (EBM). EBM operates in vacuum and preheating conditions can be easily realized thanks to the high scanning velocity of electron beam. These features are effective in reducing hot cracking during AM and make EBM the most suitable AM technology for $\mathrm{TiAl}^{[4]}$.

During the AM process, materials experience cyclic thermal treatment and rapid cooling, which would lead to unique microstructure and mechanical properties ${ }^{[5-7]}$. When applied in low pressure turbine (LPT) blades and turbochargers, for example, the mechanical properties and stability of EBM TiAl are of essential importance ${ }^{[8]}$. This article reviews the mechanical properties of TiAl fabricated by the EBM method. The processing-microstructure-property relationship, and their anisotropy is discussed based on EBM TiAl. 


\section{Static properties}

The tensile and compression properties of TiAl produced by EBM under different conditions are listed in Table 1 and Table 2.
Test orientations are designated as $X Y, Z$ or $45^{\circ}$ when the loading axis is perpendicular, parallel or with an angle of $45^{\circ}$ to the building direction, respectively.

Table 1: Tensile properties of some EBM TiAl alloys at room temperature

\begin{tabular}{|c|c|c|c|c|c|c|}
\hline Alloy & Condition & Test orientation & $\begin{array}{l}\text { Yield strength } \\
(\mathrm{MPa})\end{array}$ & $\begin{array}{l}\text { Ultimate tensile } \\
\text { strength (MPa) }\end{array}$ & Elongation (\%) & Ref. \\
\hline \multirow{16}{*}{$\begin{array}{c}\text { Ti-48Al-2Nb-2Cr } \\
(4822)\end{array}$} & HT-DP & & $\sim 353$ & $\sim 469$ & 1.10 & \multirow{2}{*}{ [9] } \\
\hline & HIP-Equiaxed & NA & $\sim 374$ & $\sim 434$ & 1.15 & \\
\hline & \multirow{3}{*}{ As-built } & $z$ & 605 & $\sim 640$ & $\sim 0.5$ & \multirow{3}{*}{ [10] } \\
\hline & & $45^{\circ}$ & 566 & $\sim 715$ & $\sim 2.8$ & \\
\hline & & $X Y$ & 587 & $\sim 630$ & $\sim 2.1$ & \\
\hline & As-built & z & $555 \pm 11$ & $603 \pm 18$ & $0.94 \pm 0.06$ & [11] \\
\hline & HIP-DP & 1 & 370 & 460 & 2 & [12] \\
\hline & \multirow{2}{*}{ HIP-Equiaxed } & $X Y$ & $449 \pm 15$ & $531 \pm 20$ & $2.42 \pm 0.38$ & \multirow{6}{*}{ [13] } \\
\hline & & Z & $466 \pm 15$ & $501 \pm 25$ & $1.3 \pm .67$ & \\
\hline & \multirow{2}{*}{$\mathrm{HIP}+\mathrm{HT}(\mathrm{DP})$} & $X Y$ & $354 \pm 3$ & $478 \pm 4$ & $2.29 \pm 0.03$ & \\
\hline & & Z & $382 \pm 10$ & $474 \pm 23$ & $1.25 \pm 0.35$ & \\
\hline & \multirow{2}{*}{$\mathrm{HIP}+\mathrm{HT}(\mathrm{FL})$} & $X Y$ & $368 \pm 10$ & $461 \pm 1$ & $1.5 \pm 0.08$ & \\
\hline & & Z & $372 \pm 13$ & $429 \pm 26$ & $0.8 \pm 0.2$ & \\
\hline & As-built & $X Y$ & & $436-561$ & Before yielding & \multirow{2}{*}{ [14] } \\
\hline & HIP & $X Y$ & $546 \pm 25$ & $641 \pm 25$ & $2.66 \pm 0.65$ & \\
\hline & Cast (DP) & 1 & 329 & 465 & 2.4 & [15] \\
\hline $\begin{array}{c}\text { Ti-48Al-2Nb- } \\
0.7 \mathrm{Cr}-0.3 \mathrm{~S}\end{array}$ & $\mathrm{HT}(\mathrm{NL})$ & NA & $253 \pm 13$ & $336 \pm 26$ & $0.27 \pm 0.1$ & [16] \\
\hline \multirow{4}{*}{$\begin{array}{c}\text { Ti-47Al-2Nb-2Cr } \\
(4722)\end{array}$} & As-built & $X Y$ & NA & $556-684$ & $0.31-0.70$ & [17] \\
\hline & As-built & $z$ & $462-530$ & $462-568$ & $0.27-0.98$ & [18] \\
\hline & Forged & 1 & 500 & 612 & 0.9 & [19] \\
\hline & Cast & 1 & & $570 \pm 20$ & $0.48 \pm 0.05$ & [20] \\
\hline \multirow{2}{*}{ Ti-45Al-4Nb-C } & As-built (DP) & NA & 1 & $\sim 460$ & $\sim 0.26$ & \multirow{2}{*}{ [21] } \\
\hline & Heat treated (FL) & NA & 1 & $\sim 350$ & $\sim 0.16$ & \\
\hline \multirow{4}{*}{ Ti-45Al-8Nb } & As-built (NL) & & NA & 710 & & \multirow{4}{*}{ [22] } \\
\hline & As-built (DP) & $z$ & NA & 715 & Before yielding & \\
\hline & As-built (Equiaxed) & & NA & 670 & & \\
\hline & Cast (FL) & 1 & NA & 580 & NA & \\
\hline
\end{tabular}

Note: HT-heat treated, HIP-hot isostatic pressed, DP-duplex, NL-nearly lamellar, FL-fully lamellar.

Table 2: Compression properties of some EBM TiAl alloys

\begin{tabular}{|cccccc|}
\hline Alloy & Condition & $\begin{array}{c}\text { Yield strength } \\
(\mathrm{MPa})\end{array}$ & $\begin{array}{c}\text { Compressive } \\
\text { strength }(\mathrm{MPa})\end{array}$ & Strain & Reference \\
\hline Ti-45Al-7Nb-0.3W & As-built & & $2,029-2,751$ & $31.92-37.03$ & {$[23]$} \\
4722 & As-built & & $2,457-2,930$ & $27.5-35.6$ & {$[24]$} \\
4822 & As-built & $726-754$ & & & {$[25]$}
\end{tabular}




\subsection{Processing-microstructure-property relationship}

According to Table 1, EBM TiAl usually presents higher ultimate tensile strength than their cast counterparts. However, significant variations in strength and ductility are revealed, which can be ascribed to the different processing parameters utilized during EBM. According to Kan et al. ${ }^{[22]}$, as preheating beam current increases from $24 \mathrm{~mA}$ to $26 \mathrm{~mA}$, microstructure of as-built Ti-45Al-8Nb changes from equiaxed $\gamma$ to nearly lamellar (i.e. volume fraction of lamellar colonies increases) and the ultimate tensile strength at room temperature (RT) increases from $670 \mathrm{MPa}$ to $710-715 \mathrm{MPa}$ (Fig. 1). Chen and Yue et al. ${ }^{[17,18,26,27]}$ reported the influence of melting beam current, scanning speed and hatching distance on microstructure and compressive/tensile properties of TiAl4722. Generally, a lower beam current, faster scanning speed and longer hatching distance yield finer grains and therefore higher strength ${ }^{[17]}$. When the scanning speed further increases to $2,400 \mathrm{~mm} \cdot \mathrm{s}^{-1}$, the tensile strength decreases due to the porosity caused by lack-of-fusion (Table 3 ).
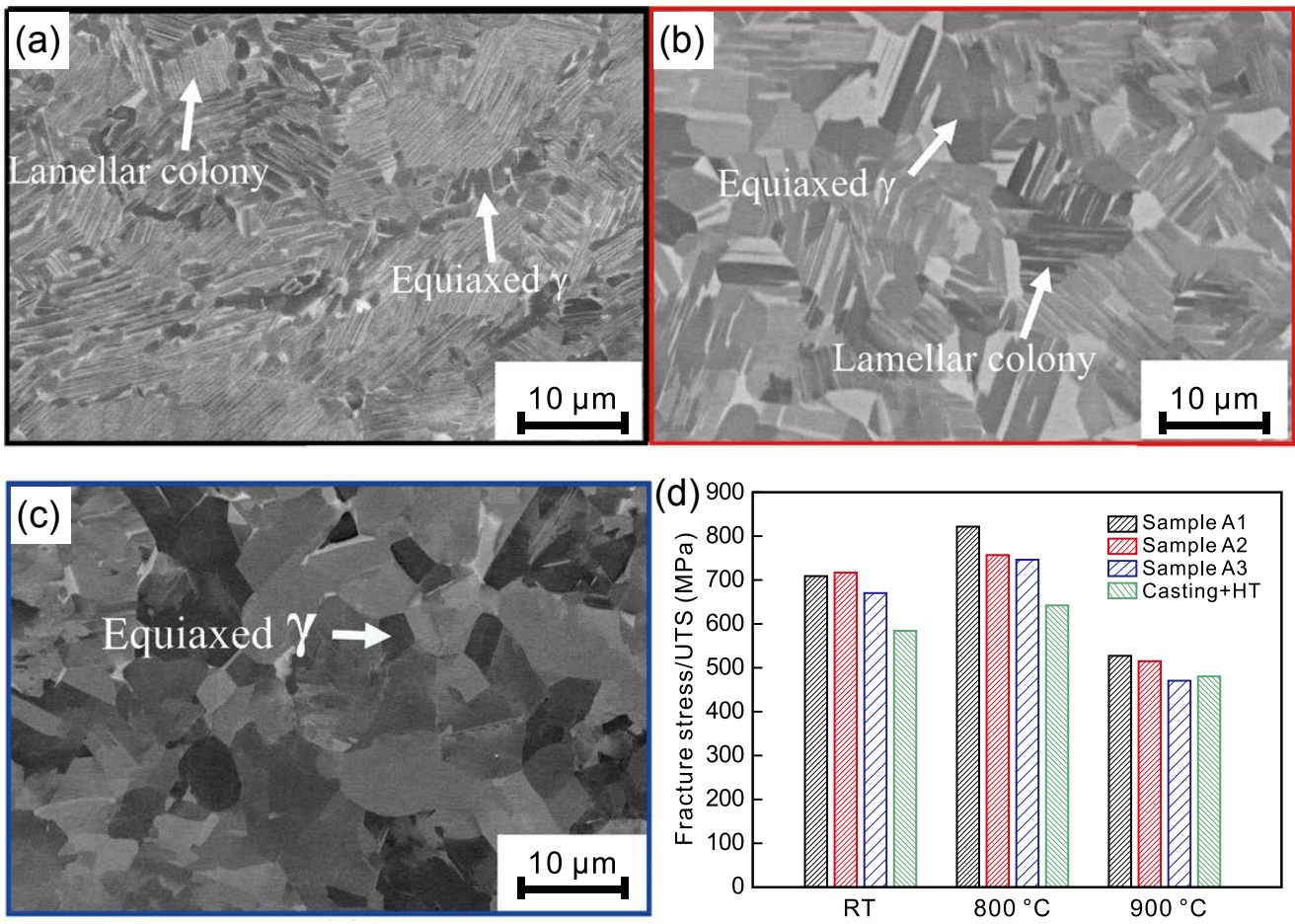

Fig. 1: SEM graphs of EBM Ti-45AI-8Nb samples fabricated with different preheating beam current (A): (a) nearly fully lamellar when A1 = 26 mA; (b) duplex when A2 = 25 mA; (c) near equiaxed $\gamma$ when A3 = 24 mA; (d) tensile properties of samples ${ }^{[22]}$

Table 3: Porosity and tensile properties as a function of scanning speed in EBM TiAl-4722 ${ }^{[17]}$

$\begin{array}{cccc}\text { Scanning speed }\left(\mathrm{mm} \cdot \mathrm{s}^{-1}\right) & \text { Porosity }(\%) & \text { UTS }(\mathrm{MPa}) & \text { Elongation }(\%) \\ 1,500 & 0.186 & 626 \pm 8 & 0.47 \pm 0.03 \\ 1,800 & 0.243 & 663 \pm 12 & 0.50 \pm 0.04 \\ 2,100 & 0.292 & 684 \pm 7 & 0.70 \pm 0.06 \\ 2,400 & 0.686 & 556 \pm 15 & 0.31 \pm 0.04\end{array}$

\subsection{Anisotropy in tensile properties}

Anisotropy in mechanical properties of AM metals, including titanium alloys, superalloys, stainless steels and aluminum alloys have been widely reported ${ }^{[7]}$. In most cases, the anisotropy in tensile properties, especially ductility, is attributed to the columnar grains, texture, and defects such as lack-of-fusion and porosity.

As-built EBM TiAl-4822 exhibits a layered microstructure (Fig. 2). Todai et al. ${ }^{[10]}$ found that the total thickness of one duplex band and one $\gamma$ band equals to the thickness of each powder layer. It is believed that the layered microstructure is a result of the cyclic heat treatment by the electron beam on the solidified material. In addition, the anisotropic tensile properties of TiAl-4822 are shown in Table 1 and Fig. 3. The microstructure after deformation shows an aggregation of slip/ twin traces in $\gamma$ bands, indicating the $\gamma$ bands deform more easily than the duplex band. As the shear stress is parallel to the soft $\gamma$ bands in the $45^{\circ}$ sample, shear deformation occurs in the $\gamma$ bands and therefore results in a greater elongation ${ }^{[10]}$.

According to Lin et al. ${ }^{[13]}$, the anisotropy of tensile properties 


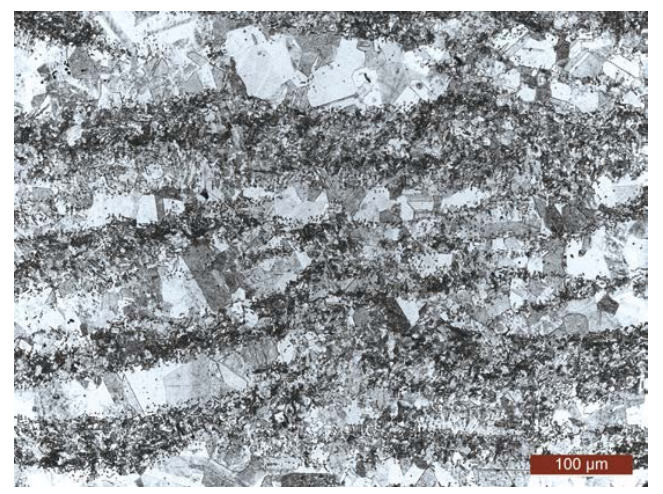

Fig. 2: Typical layered microstructure of as-built EBM TiAl-4822

(a)

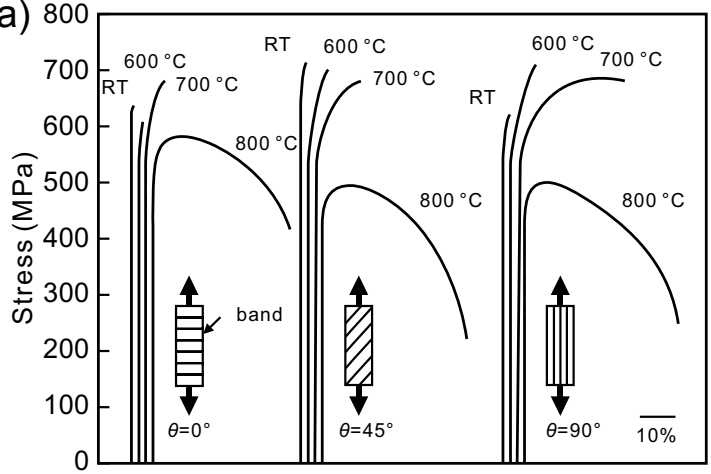

Plastic strain $(\%)$ cannot be eliminated by HIP or heat treatment. For EBM TiAl-4822 with equiaxed (HIP condition), duplex and fully lamellar microstructure, samples along $Z$ direction show a lower ductility compared with those along $X Y$ direction. For the HIP- $Z$ samples, the cracks initiated by the cleavage of coarse $\gamma$ grains; while for the HIP- $X Y$ samples, cracks initiated by both cleavage and intergranular cracking of coarse $\gamma$ grains [Fig. 4(a, b)]. Lamellae nearly perpendicular to the loading axis, in which crack initiates and propagates more easily, are more frequently observed for DP- $Z$ (duplex condition) and FL-Z (fully lamella) samples [Fig. 4(c, d)]. This preferential orientation is caused by the strong texture of $\alpha 2$ phase with its (0001) nearly perpendicular to the building direction. When
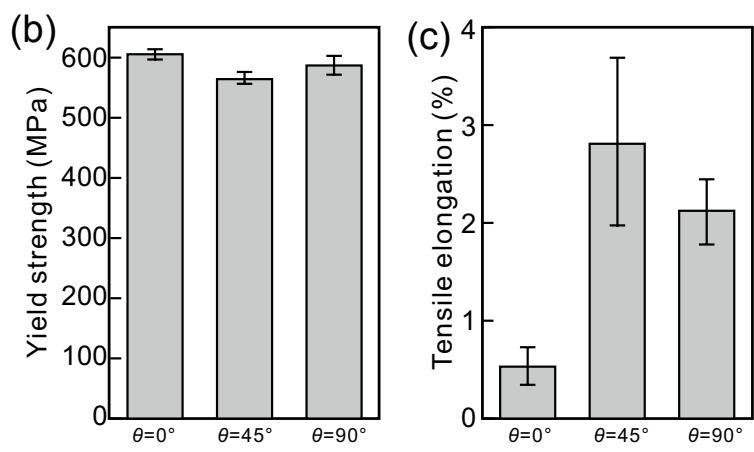
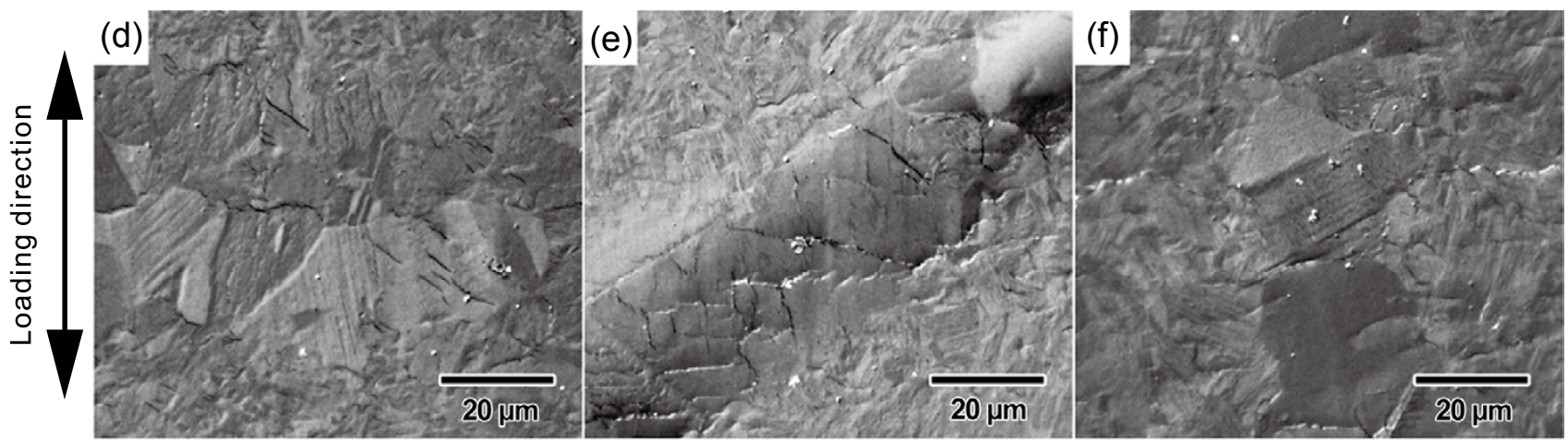

Fig. 3: Tensile stress-strain curves of as-built EBM TiAl-4822 alloy deformed with $\theta=0^{\circ}(Z), 45^{\circ}$ and $90^{\circ}(X Y)$ at different temperatures (a), variation in yield strength (b) and elongation (c) of specimens at room temperature, and side view of $\theta=0^{\circ}(\mathrm{d}), 45^{\circ}(\mathrm{e})$ and $90^{\circ}$ (f) sample after tensile test at room temperature ${ }^{[10]}$

subjected to heat treatment, the formation of $\gamma$ bands from $\alpha /$ $\alpha 2$ follows the Blackburn-orientation relationship ${ }^{[28]}$ : (0001) $\alpha 2 / /\{111\} \gamma$ and $<1120>\alpha 2 / /[110] \gamma$, and forms the preferential orientation of lamellae.

Yue et al. ${ }^{[26,27]}$ studied the effect of processing parameters on anisotropy of as-built TiAl-4722. When increasing the energy density from 14.28 to $35 \mathrm{~J} \cdot \mathrm{mm}^{-3}$, the microstructure transforms from fine duplex to coarse epitaxial columnar. Meanwhile, preferential orientation of lamellae becomes more obvious with the increase of energy density. With low energy densities $\left(<20 \mathrm{~J} \cdot \mathrm{mm}^{-3}\right)$, no preferential orientation is observed. With high energy densities, however, $80 \%$ of the lamellae have traces with an angle of $0^{\circ} \pm 5^{\circ}$ or $45^{\circ} \pm 5^{\circ}$ to the building direction. Difference in tensile properties between $X Y$ and $Z$ samples increases with an increase in energy density, and the ductility of $X Y$ sample is only half of $Z$ sample with energy density. After heat treatment in the single $\alpha$ phase field, the degree of anisotropy is weakened.

\subsection{Fracture toughness}

In the limited literature concerning fracture toughness of EBM TiAl, porosity is found to play an important role. According to Seifi et al. ${ }^{[25]}$, after removal of the regions containing a great number of pores, toughness increases and scattering reduces ('square' compared with 'round' in Fig. 5). After HIP, most of the pores are eliminated, toughness further increases, and the toughness values varies less (Fig. 5). Toughness values of as-built $\left(24.1 \mathrm{MPa} \cdot \mathrm{m}^{1 / 2}\right)$ and HIP $\left(27.8 \mathrm{MPa} \cdot \mathrm{m}^{1 / 2}\right)$ material are comparable to that of conventionally cast material (24-25 MPa $\cdot \mathrm{m}^{1 / 2}[29]$. 

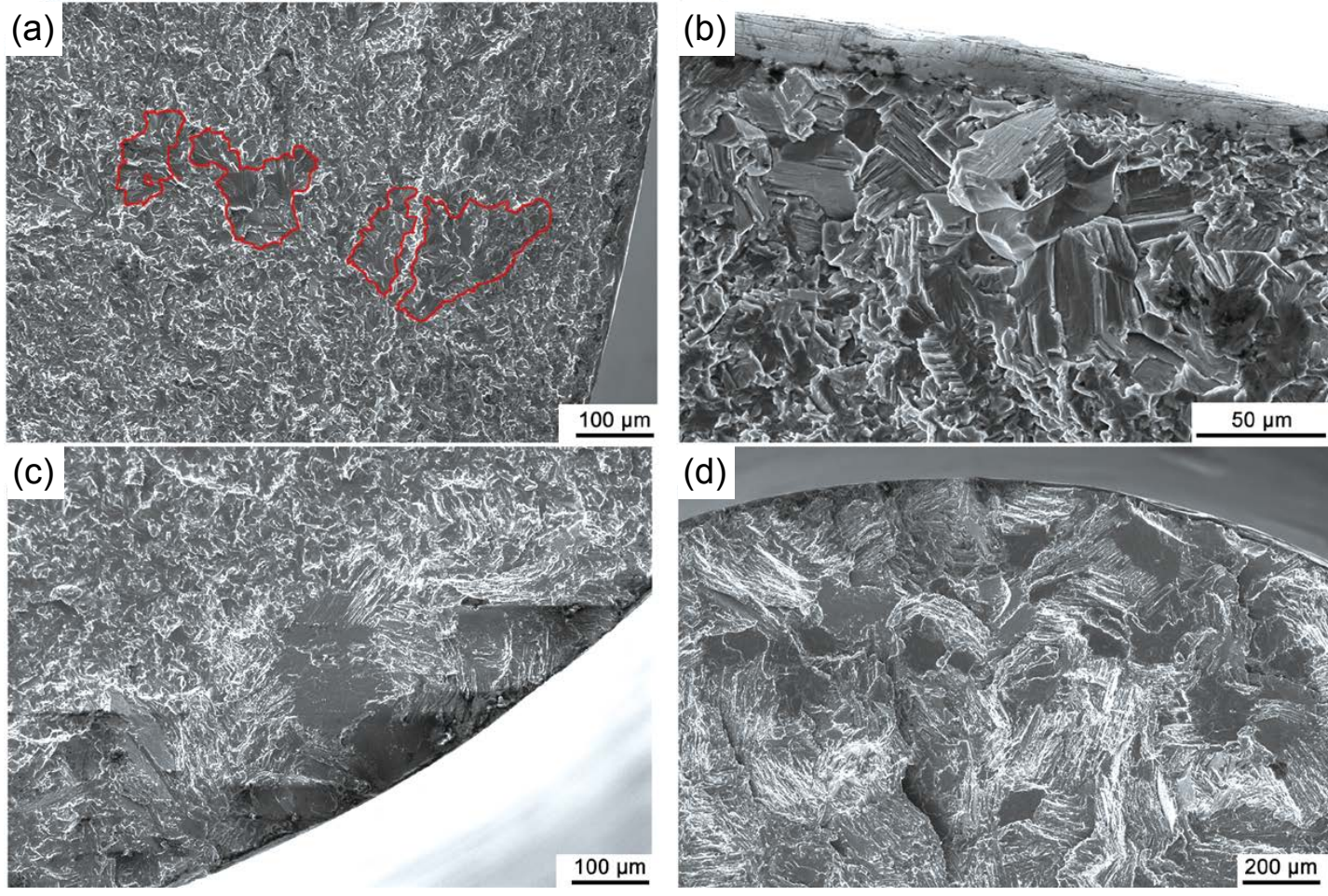

Fig. 4: Typical crack initiation in EBM TiAl-4822 by cleavage of coarse y grains in HIP-Z (a), fracture and intergranular cracking of coarse $Y$ grains in HIP-XY (b), cracking of lamellae perpendicular to loading direction in DP-Z (c) and FL-Z (d) ${ }^{[13]}$

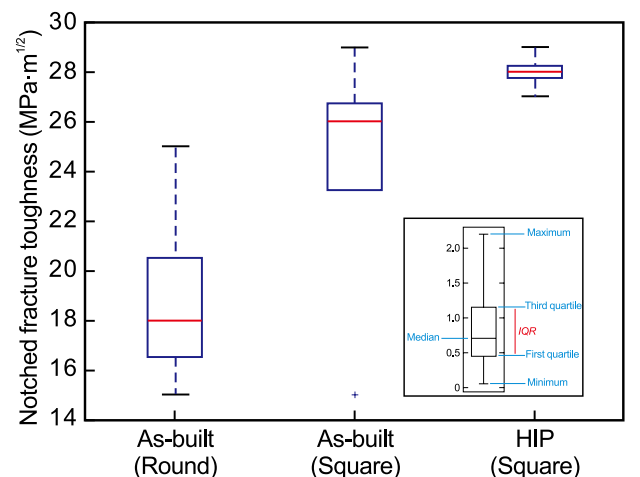

Fig. 5: Notched fracture toughness of as-deposited and HIP EBM TiAl-4822 ${ }^{[25]}$

\section{Fatigue}

\subsection{General fatigue property}

Studies on fatigue properties of EBM TiAl are limited compared with EBM Ti-6Al-4V. Most of the data are reported by Filippini, Beretta and Patriarca ${ }^{[30-33]}$, and the measured fatigue limit is shown in Table 4 . The $10^{7}$ fatigue limit is nearly independent of loading ratio, and is higher than $95 \%$ of the ultimate tensile strength (351 MPa at RT and $390 \mathrm{MPa}$ at $704{ }^{\circ} \mathrm{C}$ for TiAl-4822 ${ }^{[33]}$ ).

Cho et al. ${ }^{[34]}$ reported the anisotropic fatigue behavior of TiAl-4822 with layered microstructure at room temperature [Fig. 6(a)]. It can be seen that the fatigue property of $\theta=45^{\circ}$ ( $\theta=$ angle between building direction and loading axis) is higher than $\theta=0^{\circ}$ and is comparable to cast + HIP counterparts. It is believed that the main crack initiation is inhibited by stress
Table 4: Fatigue strength of EBM TiAl-4822 and TNB ${ }^{[30,32]}$

$\begin{array}{cccc}\text { Temperature } & \begin{array}{c}\text { Loading ratio } \\ (R)\end{array} & \text { Fatigue limit }\left(10^{7}\right)(\mathrm{MPa}) \\ \text { RT } & -1 & 4822 & \text { TNB } \\ \text { RT } & 0 & 335 & - \\ \text { RT } & 0.6 & 340 & - \\ 704^{\circ} \mathrm{C} & 0 & 370 & - \\ 704{ }^{\circ} \mathrm{C} & 0.6 & 390 & 416\end{array}$

relaxation due to the shear deformation along the $\gamma$ bands in $\theta=45^{\circ}$. Kernel average misorientation (KAM) maps were taken before and after $10^{5}$ cycles at the same location on the fatigue sample surface ${ }^{[34]}$. The results vary for different angles. When $\theta=0^{\circ}$, no significant difference in the KAM value before and after the fatigue tests is observed [Fig. 7(a,b)]. In contrast, when $\theta=45^{\circ}$, the KAM value in the $\gamma$ band increases after the fatigue tests, while no significant change in the KAM is observed in the duplex-like region [Fig. 7(c, d)]. TEM results further confirm that there are more concentrated dislocations in $\gamma$ band [Fig. 7(e, f)]. At $750{ }^{\circ} \mathrm{C}(1,023 \mathrm{~K})$, similar stress-life curves were obtained for $\theta=0^{\circ}$ and $\theta=45^{\circ}$ [Fig. 6(b)]. The greater slope in the high cycle region is ascribed to the combination effect of low plastic hysteresis energy (Ep), intergranular fracture within the $\gamma$ bands and weakened work hardening.

In another study on strain distribution under static and 
(a)

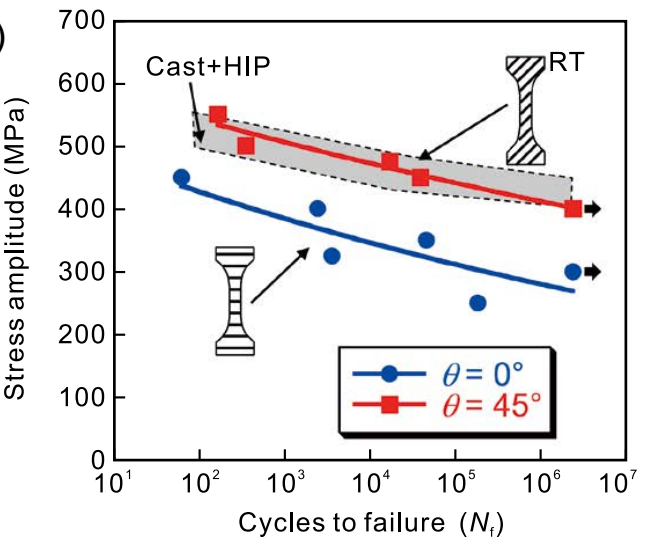

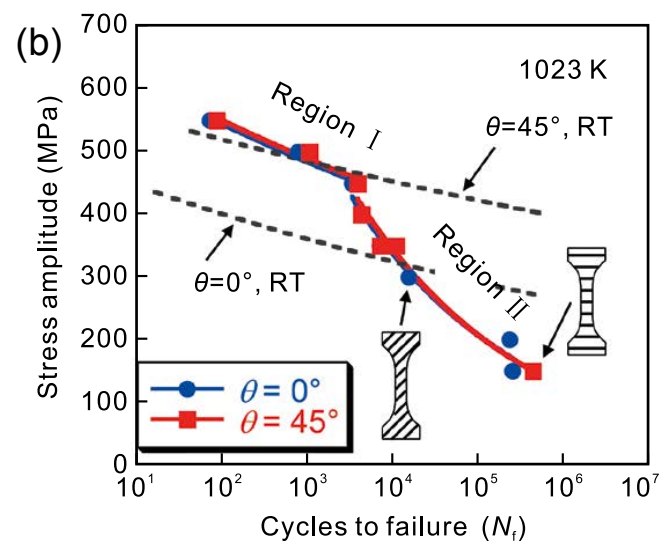

Fig. 6: $S-N_{f}$ curves of TiAl- 4822 at $\theta=0^{\circ}$ and $\theta=45^{\circ}$ cyclically deformed at RT (a) and $750{ }^{\circ} \mathrm{C}(1,023 \mathrm{~K})(\mathrm{b}), \mathrm{S}-\mathrm{N}_{\mathrm{f}}$ curves of cast alloys with HIP treatment at RT are also listed for comparison ${ }^{[34]}$
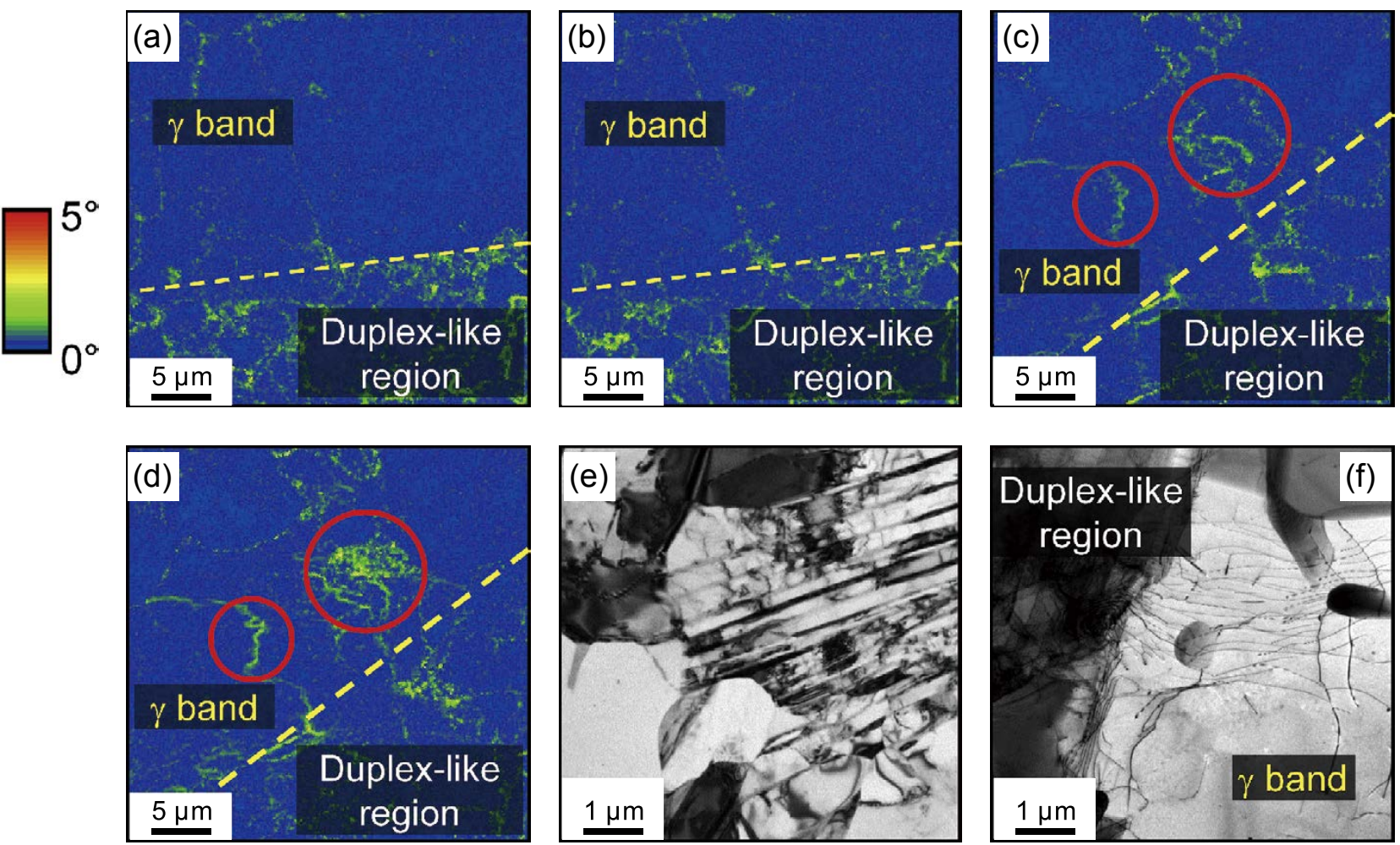

Fig. 7: EBSD KAM maps of $\theta=0^{\circ}(a, b)$ and $\theta=45^{\circ}(c, d)$ before $(a, c)$ and after (b, d) fatigue tests at RT, $\sigma=300 \mathrm{MPa}$, $N=1 \times 10^{5}$ cycles; TEM bright-field images of dislocation structure in fatigued $\theta=45^{\circ}(e, f)$ showing duplex-like region (e) and duplex-like region/ $\gamma$ band interface $(f){ }^{[34]}$

cyclic loadings of a duplex TiAl-4822, ex-situ high-resolution digital image correlation (DIC) was utilized ${ }^{[31]}$. The largest strain locations were found in 'soft' oriented lamellar colonies (interfaces oriented approximately $45^{\circ}$ with respect to loading axis) (Fig. 8). Further, the combination of DIC technique with SEM and BSE images shows that in a lamellar colony, strain is localized in the $\gamma$ platelets (Fig. 9). In the study by Bode et al. ${ }^{[35]}$, the local strain field during fatigue test was also monitored by DIC. Similarly, higher shear strains were observed in soft oriented lamellar colonies. However, no cracks initiated from these lamellar colonies, and only one crack initiated in a hard oriented lamellar colony. In this colony, the total strain of normal and shear components is moderate compared with soft oriented colonies, but the normal strain perpendicular to the lamella is the highest. Fracture surface of a sample confirms the crack initiation from a hard oriented lamellar colony (Fig. 10) ${ }^{[30]}$.

\subsection{Effect of defects on fatigue property}

Figure 11 shows the fatigue properties of EBM TiAl-4822 with defects. Variation in fatigue life can be as large as 3 orders of magnitude for the same stress amplitude. Facets (cracked colonies with extra-large size) and pores are the most common defects, and facets are more harmful as they are usually larger in size and lead to a shorter fatigue life. For example, in Fig. 12, the biggest pore observed is $25 \mu \mathrm{m}$ in length, which is much smaller compared with facets (usually $70 \mu \mathrm{m}$ in diameter). 


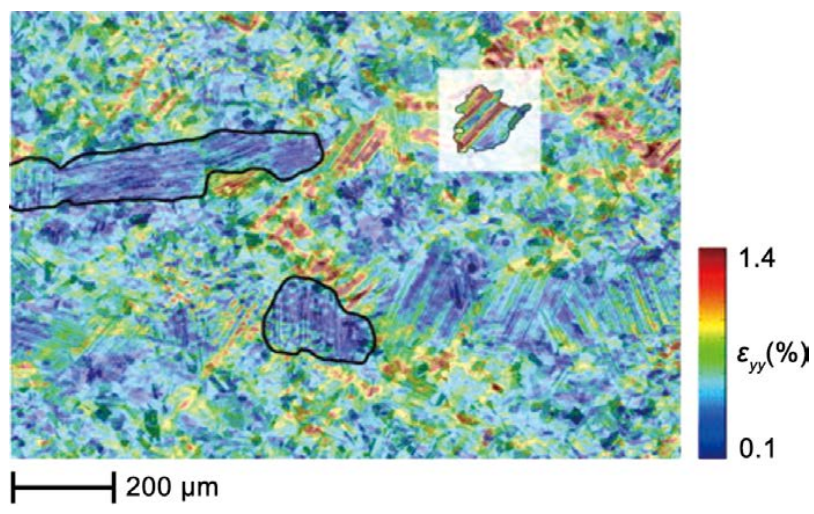

Fig. 8: Strain field acquired by DIC on EBM TiAl-4822 after cyclic loading showing strain concentration in soft oriented lamellar colonies ${ }^{[31]}$
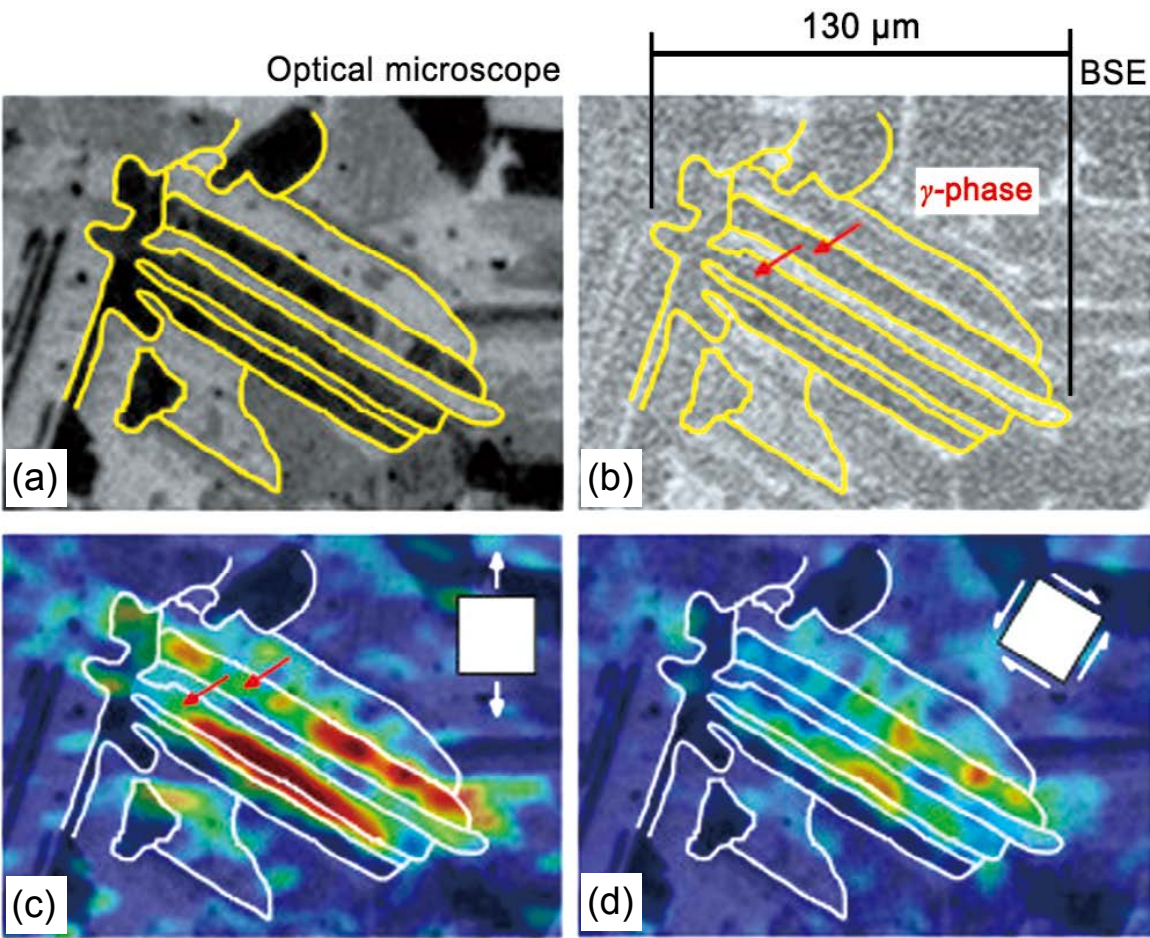

$\varepsilon_{y y}(\%)$

0.2
Filippini ${ }^{[30]}$ studied the fatigue behavior of EBM TiAl4822 with artificial defects introduced by electron discharged machining. The modified El-Haddad/Tanka model can describe the relationship between threshold stress range and defect size. As shown in Fig. $13^{[30]}$, the unfavorably oriented colonies where fatigue cracks initiate are treated as inherent defects (plain samples), the average area of which is $22,000 \mu \mathrm{m}^{2}$ $\left[(\text { area })^{1 / 2} \approx 150 \mu \mathrm{m}\right]$. This further confirms the detrimental effect of extra-large colonies.

Fig. 9: Strain localization for a fatigue experiment in compression: OM image (a) and BSE image (b) of lamellar grain; and DIC technique combined with BSE images shows the strain location for $\gamma$-phase of lamellar grain (c) and (d) ${ }^{[31]}$

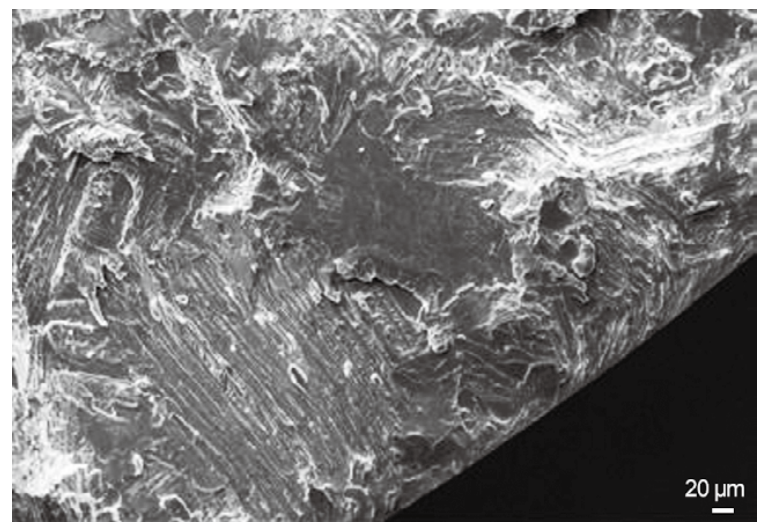

Fig. 10: Typical crack initiation site found in fatigue tests: specimen failed after $3.2 \times 10^{6}$ cycles $\left(R=\sigma_{\min } / \sigma_{\max }=0 ; \sigma_{\max }=340 \mathrm{MPa}\right)^{[30]}$

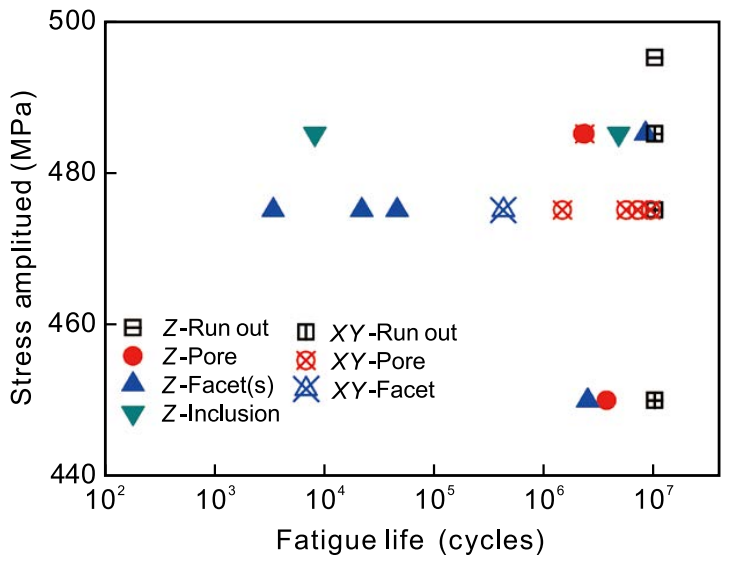

Fig. 11: Fatigue properties of EBM TiAl-4822 ( $R=0$, room temperature, flat sample) 

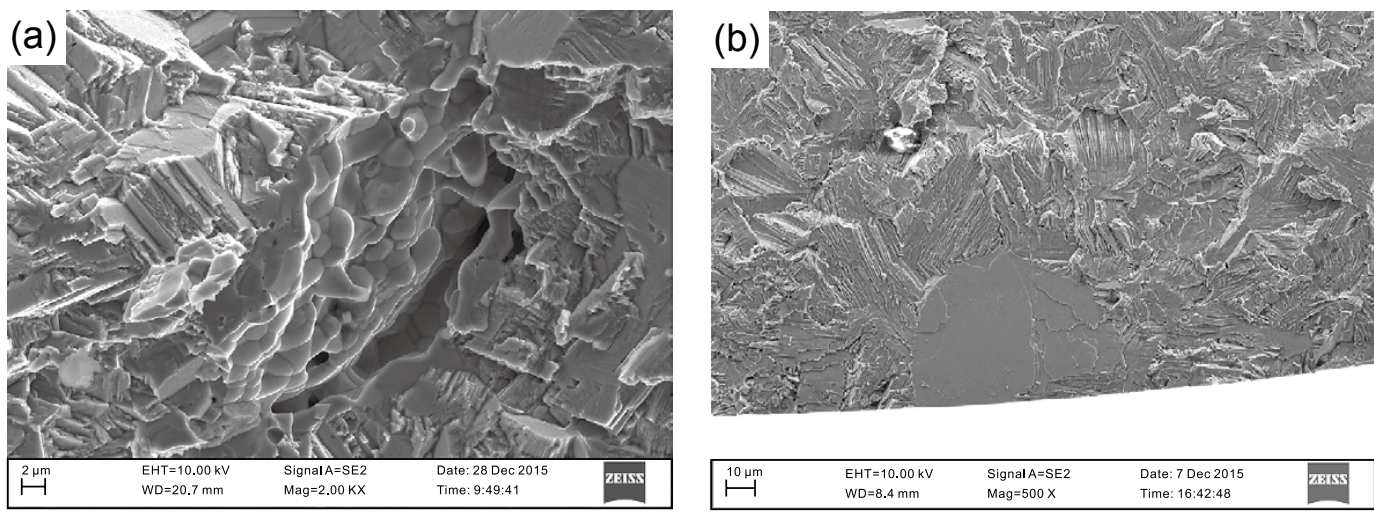

Fig. 12: Fracture surface showing fatigue crack initiation from a pore $\left(25 \mu \mathrm{m}\right.$ in length, $R=0.06, \sigma_{\max }=475 \mathrm{MPa}$, failed after $9.22 \times 10^{6}$ cycles) (a) and a facet $\left(70 \mu \mathrm{m}\right.$ in diameter, $R=0.06, \sigma_{\max }=475 \mathrm{MPa}$, failed after $4.55 \times 10^{4}$ cycles) (b)
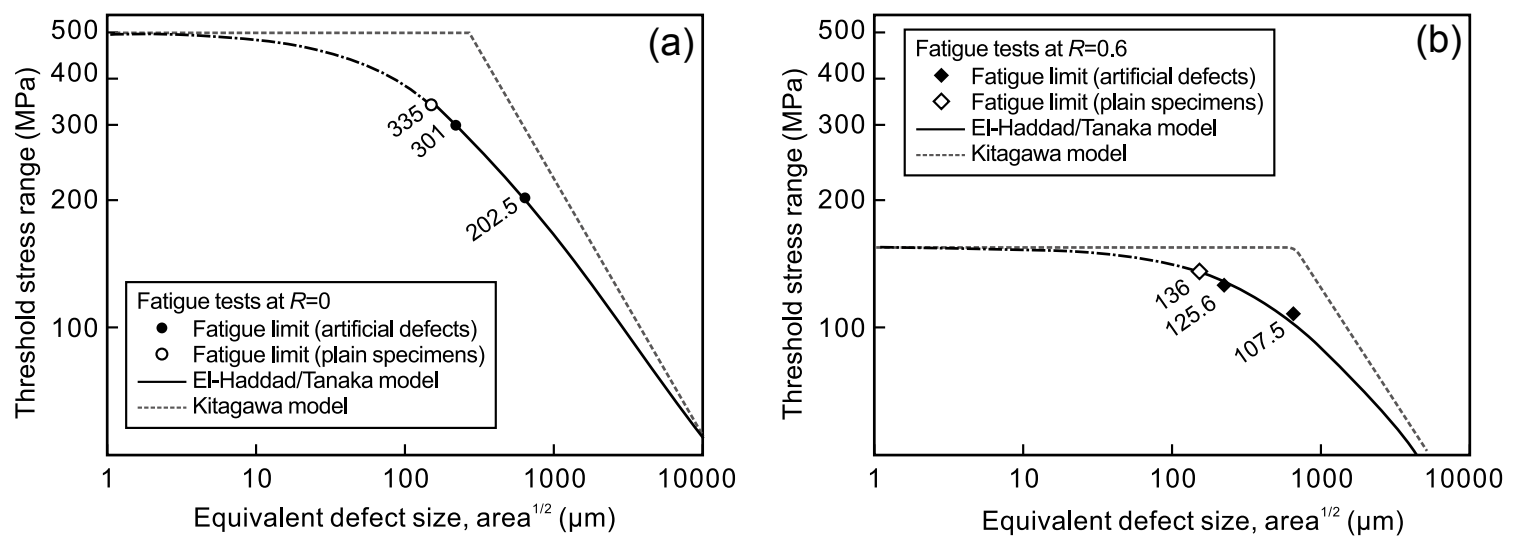

Fig. 13: Kitagawa diagram and modified El-Haddad/Tanka model for: (a) loading ratio $R=0$; (b) loading ratio $R=0.6^{\text {[30] }}$

\subsection{Fatigue crack growth}

Table 5 lists the fatigue crack propagation properties of EBM TiAl. The threshold stress intensity range $\left(K_{\mathrm{th}}\right)$ and maximum stress intensity $\left(K_{\max }\right)$ are comparable to material fabricated by conventional methods.

Table 5: Fatigue crack propagation properties of EBM TiAl

\begin{tabular}{|c|c|c|c|}
\hline Specimen condition & $\begin{array}{l}\text { Load ratio } \\
(R)\end{array}$ & $\begin{array}{c}K_{\text {th }} \\
\left(\mathrm{MPa}_{\mathrm{a}} \cdot \mathrm{m}^{1 / 2}\right)\end{array}$ & $\begin{array}{c}K_{\max } \\
\left(\mathrm{MPa}^{1 / 2}\right)\end{array}$ \\
\hline As-deposited-equiaxed ${ }^{[25]}$ & 0.3 & $8-9$ & $13.2-13.9$ \\
\hline As-HIP-equiaxed ${ }^{[25]}$ & 0.1 & 13 & 18.2 \\
\hline Heat treated-duplex ${ }^{[36]}$ & 0.05 & 6 & 10.8 \\
\hline Heat treated-duplex ${ }^{[36]}$ & 0.6 & 3 & 11.5 \\
\hline Cast fully lamellar ${ }^{[37]}$ & 0.1 & 9.2 & 20.4 \\
\hline Forged-duplex ${ }^{[38]}$ & 0.1 & 6.0 & 8.2 \\
\hline
\end{tabular}

\section{Creep}

Juechter et al. ${ }^{[21,39]}$ investigated the creep properties of EBM TiAl-4822 at $900{ }^{\circ} \mathrm{C}$. For the as-built alloy, the minimum creep rate is one order of magnitude higher than the fully lamellar cast alloy ${ }^{[40]}$. The creep resistance is found to increase with heat treatment temperature. After heat treated above the $\alpha$-transus temperature, the creep resistance is improved to the same level of cast alloy (Fig. 14). Similar results have been reported by Kim et al. ${ }^{[41,42]}$ in a multi-step compression creep test at $750{ }^{\circ} \mathrm{C}$. The improvement of creep resistance with higher lamellar colonies fraction is due to the lamellae interfaces that act as barriers to dislocation movement ${ }^{[43]}$.

Baudana et al. ${ }^{[16]}$ tested the creep properties of EBM Ti$48 \mathrm{Al}-2 \mathrm{Nb}-0.7 \mathrm{Cr}-0.3 \mathrm{Si}$, which was used in the fabrication of a turbocharger. After heat treated to a nearly lamellar microstructure, the creep properties are comparable to the material processed by conventional method (Table 6).

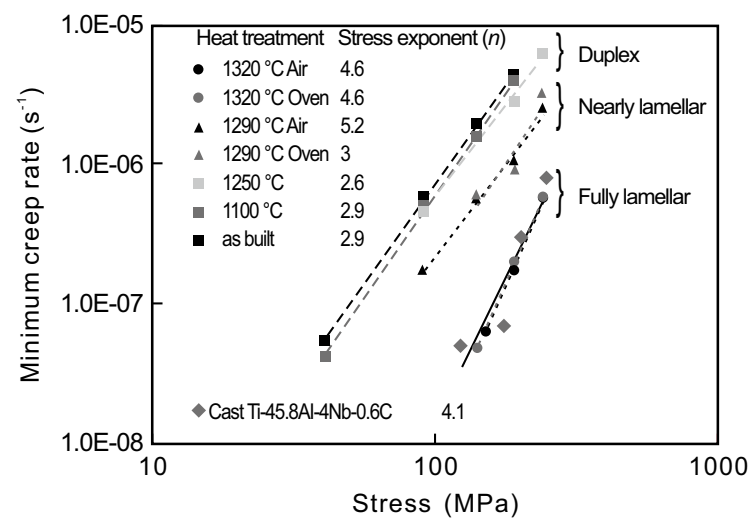

Fig. 14: Measured minimum creep rate in dependence of heat treatment conditions at a test temperature of $900{ }^{\circ} \mathrm{C}$ and compressive loading ${ }^{[21]}$ 
Table 6: Creep test results of Ti-48AI-2Nb-0.7Cr-0.3Si heat treated at $800{ }^{\circ} \mathrm{C}$ with $\mathrm{NL}^{[16]}$

\begin{tabular}{|c|c|c|c|c|c|}
\hline $\begin{array}{l}\text { Stress } \\
(\mathrm{MPa})\end{array}$ & $\begin{array}{c}\text { Final creep } \\
(\%)\end{array}$ & $\begin{array}{c}\text { Elongation } \\
(\%)\end{array}$ & $\begin{array}{l}\text { Rupture time } \\
\text { (h) }\end{array}$ & $\begin{array}{l}\text { Larson Miller } \\
\text { parameter } \\
{\left[T\left(20 \operatorname{tlog}_{\mathrm{r}}\right)\right]^{*}}\end{array}$ & $\begin{array}{l}\text { Larson Miller parameter of cast } \\
\text { alloy with similar composition } \\
\qquad\left[T\left(20 t_{\left.\left.\log t_{\mathrm{r}}\right)\right]^{*}}\right.\right.\end{array}$ \\
\hline 200 & 5.72 & 6.8 & 372 & 24.22 & 24.3 \\
\hline 300 & 8.32 & 9.8 & 23.7 & 22.93 & 23.1 \\
\hline
\end{tabular}

${ }^{*} T$ : temperature $(\mathrm{K}), t$ : time $(\mathrm{h}), t_{\mathrm{r}}$ : rupture time $(\mathrm{h})$.

\section{Summary}

The tensile and compression properties, fracture toughness, fatigue and creep properties of EBM TiAl were compared with those of conventional methods. Summaries can be obtained as follows:

(1) The as-built EBM TiAl has higher tensile strength than cast alloys. Other properties are comparable to cast alloys except the creep resistance. With the increased fraction of lamellar colonies, the creep resistance can be improved to the same level of as-cast alloys.

(2) The microstructure and mechanical properties of EBM TiAl are sensitive to processing parameters. Small changes in beam current and scanning speed have a strong effect on the phase composition, morphology and number of defects, resulting in a great variation in properties.

(3) Anisotropy exists in tensile and fatigue properties. Strain localization in the $\gamma$ layer and preferential orientation resulting from texture are the main factors.

(4) HIP is effective in reducing the scatter in fracture toughness, but scatter still exists in fatigue property of materials after HIP. Facets are larger in size than pores and therefore more detrimental to fatigue property.

Materials for crucial parts in jet engines must demonstrate high reliability in the operating environment. EBM additive manufacturing demonstrates its feasibility for making complex TiAl components with good mechanical properties. TiAl has a greater sensitivity to chemical, microstructural, manufacturing, and service discontinuities comparing with other Ti alloys, so the control of EBM processing parameters is more important when making TiAl. This requires a deep understanding of the variations in material properties that result from defects introduced during additive manufacturing, such as porosity, inhomogeneous chemistry, and layered microstructure. High fidelity models and lifing methodologies for EBM TiAl should be developed to continually improve the stability of mechanical properties. This will guarantee the qualified rate of products and flight safety when entering the mass production stage of TiAl components.

\section{Acknowledgement}

This work was financially supported by the Defense Industrial Technology Development Program (Grant No. JCKY2017205A002).

\section{References}

[1] Dimiduk D M. Gamma titanium aluminide alloys - An assessment within the competition of aerospace structural materials. Materials Science and Engineering: A, 1999, 263(2): 281-288.

[2] Kim Y W. Ordered intermetallic alloys, part III: Gamma titanium aluminides. JOM, 1994, 46(7): 30-39.

[3] Bewlay B P, Nag S, Suzuki A, et al. TiAl alloys in commercial aircraft engines. Materials at High Temperatures, 2016, 33(45): 549-559.

[4] Löber L, Biamino S, Ackelid U, et al. Comparison of selective laser and electron beam melted titanium aluminides. In: Proc. 22nd International Solid Freeform Fabrication Symposium, University of Texas, Austin, 2011: 547-556.

[5] Wang F, Williams S, Colegrove P, et al. Microstructure and mechanical properties of wire and arc additive manufactured Ti-6Al-4V. Metallurgical and Materials Transactions A, 2013, 44(2): 968-977.

[6] Kelly S M, Kampe S L. Microstructural evolution in laserdeposited multilayer Ti-6Al-4V builds: Part I. Microstructural characterization. Metallurgical and Materials Transactions A, 2004, 35(6): 1861-1867.

[7] Kok Y, Tan X P, Wang P, et al. Anisotropy and heterogeneity of microstructure and mechanical properties in metal additive manufacturing: A critical review. Materials \& Design, 2018, 139: 565-586.

[8] Lasalmonie A. Intermetallics: Why is it so difficult to introduce them in gas turbine engines? Intermetallics, 2006, 14(10): 1123-1129.

[9] Biamino S, Penna A, Ackelid U, et al. Electron beam melting of Ti-48Al-2Cr-2Nb alloy: Microstructure and mechanical properties investigation. Intermetallics, 2011, 19(6): 776-781.

[10] Todai M, Nakano T, Liu T, et al. Effect of building direction on the microstructure and tensile properties of $\mathrm{Ti}-48 \mathrm{Al}-2 \mathrm{Cr}$ $2 \mathrm{Nb}$ alloy additively manufactured by electron beam melting. Additive Manufacturing, 2017, 13: 61-70.

[11] Wang J, Yang K, Liu N, et al. Microstructure and tensile properties of Ti-48Al-2Cr-2Nb rods additively manufactured by selective electron beam melting. JOM, 2017, 69: 2751-2755.

[12] Tönnes $C$, Rösler J, Baumann R, et al. Structural Intermetallics. TMS, Warrendale, PA, USA, 1993: 241.

[13] Lin B, Chen W, Yang Y, et al. Anisotropy of microstructure and tensile properties of Ti-48Al-2Cr-2Nb fabricated by electron beam melting. Journal of Alloys and Compounds, 2020, 830: 154684.

[14] Cakmak E, Nandwana P, Shin D, et al. A comprehensive study on the fabrication and characterization of $\mathrm{Ti}-48 \mathrm{Al}-2 \mathrm{Cr}-2 \mathrm{Nb}$ preforms manufactured using electron beam melting. Materialia, 2019, 6: 100284

[15] Kelly T J, Juhas M C, Huang S C. Effect of a B2/gamma structure on the tensile properties of the cast gamma titanium aluminide Ti-48Al-2Cr-2Nb. Scripta Metallurgica et Materialia, 1993, 29(11): $1409-1414$. 
[16] Baudana G, Biamino S, Klöden B, et al. Electron beam melting of Ti-48Al-2Nb-0.7Cr-0.3Si: Feasibility investigation. Intermetallics, 2016, 73: 43-49.

[17] Chen $Y$ Y, Yue H Y, Wang X P. Microstructure, texture and tensile property as a function of scanning speed of Ti-47Al$2 \mathrm{Cr}-2 \mathrm{Nb}$ alloy fabricated by selective electron beam melting. Materials Science and Engineering: A, 2018, 713: 195-205.

[18] Yue $H Y$, Chen $Y Y$, Wang $X P$, et al. Microstructure, texture and tensile properties of Ti-47Al-2Cr-2Nb alloy produced by selective electron beam melting. Journal of Alloys and Compounds, 2018, 766: 450-459.

[19] Zhang S Z, Kong F T, Chen Y Y, et al. Microstructure and Mechanical Properties of as-Forged Ti-47Al-2Cr-2Nb-Y Alloy. Advanced Materials Research, 2011, 311-313: 1873-1878.

[20] Han J C, Xiao S L, Tian J, et al. Microstructure characterization and tensile properties of a Ni-containing TiAl-based alloy with heat treatment. Rare Metals, 2016, 35(1): 26-34.

[21] Juechter V, Franke M M, Merenda T, et al. Additive manufacturing of Ti-45Al-4Nb-C by selective electron beam melting for automotive applications. Additive Manufacturing, 2018, 22: 118-126.

[22] Kan W, Chen B, Jin C, et al. Microstructure and mechanical properties of a high $\mathrm{Nb}$-TiAl alloy fabricated by electron beam melting. Materials \& Design, 2018, 160: 611-623.

[23] Tang H P, Yang G Y, Jia W P, et al. Additive manufacturing of a high niobium-containing titanium aluminide alloy by selective electron beam melting. Materials Science and Engineering: A, 2015, 636: 103-107.

[24] Yue H Y, Chen $Y$ Y, Wang X P, et al. Effect of beam current on microstructure, phase, grain characteristic and mechanical properties of Ti-47Al-2 $\mathrm{Cr}-2 \mathrm{Nb}$ alloy fabricated by selective electron beam melting. Journal of Alloys and Compounds, 2018, 750: 617-625.

[25] Seifi M, Salem A A, Satko D P, et al. Effects of HIP on microstructural heterogeneity, defect distribution and mechanical properties of additively manufactured EBM Ti-48Al-2Cr-2Nb. Journal of Alloys and Compounds, 2017, 729: 1118-1135.

[26] Yue H Y, Peng H, Li R F, et al. Effect of heat treatment on the microstructure and anisotropy of tensile properties of TiAl alloy produced via selective electron beam melting. Materials Science and Engineering: A, 2021, 803: 140473.

[27] Yue H Y. Study on the microstructure and mechanical property of Ti-47Al-2Cr-2Nb alloy fabricated by selective electron beam melting. Doctoral Dissertation, Harbin: Harbin Institute of Technology, 2019.

[28] Blackburn M J. Some aspects of phase transformations in titanium alloys. In: The Science, Technology and Application of Titanium, R I Jaffee and N E Promisel, Eds., Pergamon, 1970, 633-643.

[29] McCullough C, Valencia J J, Levi C G, et al. Phase equilibria and solidification in Ti-Al alloys. Acta Metallurgica, 1989, 37(5): $1321-1336$.
[30] Filippini M, Beretta S, Patriarca L, et al. Defect tolerance of a gamma titanium aluminide alloy. Procedia Engineering, 2011, 10: 3677-3682.

[31] Patriarca L, Filippini M, Beretta S. Digital image correlationbased analysis of strain accumulation on a duplex $\mathrm{Y}$-TiAl. Intermetallics, 2016, 75: 42-50.

[32] Filippini M, Beretta S, Patriarca L, et al. Effect of the microstructure on the deformation and fatigue damage in a gamma-TiAl produced by additive manufacturing. In: Gamma Titanium Aluminide Alloys 2014, Y W Kim, W Smarsly, J Lin, et al. Eds., The Minerals, Metals \& Materials Society, 2014: 189-193.

[33] Beretta S, Filippini M, Patriarca L, et al. Fatigue properties and design criteria of a gamma titanium aluminide alloy. Key Engineering Materials, 2011, 465: 531-534.

[34] Cho K, Kobayashi R, Oh J Y, et al. Influence of unique layered microstructure on fatigue properties of Ti-48Al-2Cr-2Nb alloys fabricated by electron beam melting. Intermetallics, 2018, 95: $1-10$.

[35] Bode B, Wessel W, Brueckner-Foit A, et al. Local deformation at micro-notches and crack initiation in an intermetallic $\mathrm{Y}$-TiAlalloy. Fatigue \& Fracture of Engineering Materials \& Structures, 2016, 39(2): 227-237.

[36] Filippini M, Beretta S, Patriarca L, et al. Fatigue sensitivity to small defects of a gamma titanium aluminide alloy. Journal of ASTM International, 2012, 9(5): 1-12.

[37] Dahar M S, Seifi S M, Bewlay B P, et al. Effects of test orientation on fracture and fatigue crack growth behavior of third generation as-cast Ti-48Al-2Nb-2Cr. Intermetallics, 2015, 57: 73-82.

[38] Rosenberger A H. Effect of environment on the fatigue crack growth of gamma titanium aluminide alloys at ambient temperatures. Scripta Materialia, 2001, 44(11): 2653-2659.

[39] Juechter V, Körner C. Creep properties of Ti-48Al-2Cr-2Nb produced by selective electron beam melting. Key Engineering Materials, 2016, 704: 190-196.

[40] Hullin G. Mikrostruktur und mechanische Eigenschaften gegossener TiAl-Legierungen. Friedrich-Alexander-Universität Erlangen-Nürnberg, 2014. (In German)

[41] Kim Y K, Hong J K, Lee K A. Enhancing the creep resistance of electron beam melted gamma Ti-48Al-2Cr-2Nb alloy by using two-step heat treatment. Intermetallics, 2020, 121: 106771.

[42] Kim Y K, Youn S J, Kim S W, et al. High-temperature creep behavior of gamma Ti-48Al-2Cr-2Nb alloy additively manufactured by electron beam melting. Materials Science and Engineering: A, 2019, 763: 138138.

[43] Morris M A, Leboeuf M. Analysis of thermal and athermal deformation mechanisms during creep of $\mathrm{Y}$-TiAl alloys. Materials Science and Engineering: A, 1997, 239-240: 429-437.

[44] Koyanagi Y, Ueta S, Noda T. Development of TiAl alloy with high creep strength and manufacturability for a turbine wheel. In: 4th Int. Work. Titan. Alum., 2011: 1-15. 